\title{
Application of Ion Beam Analysis in Studies of First Wall Materials in Controlled Fusion Devices
}

\author{
Marek Rubel ${ }^{1, *(\mathbb{D}}$, Anna Widdowson ${ }^{2}$, Laura Dittrich ${ }^{1} \mathbb{D}$, Sunwoo Moon ${ }^{1} \mathbb{D}$, Armin Weckmann ${ }^{1}$ \\ and Per Petersson 1
}

1 Fusion Plasma Physics, KTH Royal Institute of Technology, 10044 Stockholm, Sweden; lauradi@kth.se (L.D.); Sunwoo@kth.se (S.M.); weckmann@kth.se (A.W.); ppeter@kth.se (P.P.)

2 Culham Centre for Fusion Energy, Abingdon OX14 3DB, UK; anna.widdowson@ukaea.uk

* Correspondence: rubel@kth.se

check for updates

Citation: Rubel, M.; Widdowson, A.; Dittrich, L.; Moon, S.; Weckmann, A.; Petersson, P. Application of Ion Beam Analysis in Studies of First Wall

Materials in Controlled Fusion

Devices. Physics 2022, 4, 37-50.

https://doi.org/10.3390/

physics 4010004

Received: 2 December 2021

Accepted: 4 January 2022

Published: 17 January 2022

Publisher's Note: MDPI stays neutral with regard to jurisdictional claims in published maps and institutional affiliations.

Copyright: (c) 2022 by the authors. Licensee MDPI, Basel, Switzerland. This article is an open access article distributed under the terms and conditions of the Creative Commons Attribution (CC BY) license (https:// creativecommons.org/licenses/by/ $4.0 /)$.

\begin{abstract}
The paper provides a concise overview of ion beam analysis methods and procedures in studies of materials exposed to fusion plasmas in controlled fusion devices with magnetic confinement. An impact of erosion-deposition processes on the morphology of wall materials is presented. In particular, results for deuterium analyses are discussed. Underlying physics, advantages and limitations of methods are addressed. The role of wall diagnostics in studies of material migration and fuel retention is explained. A brief note on research and handling of radioactive and beryllium-contaminated materials is also given.
\end{abstract}

Keywords: ion beam analysis; plasma facing materials; hydrogen isotopes; Joint European Torus (JET); Torus Experiment for Technology Oriented Research (TEXTOR)

\section{Introduction}

The ultimate goal of research in the field of controlled thermonuclear fusion of light nuclei is to construct and operate an energy-generating system for sustainable electricity production. The development involves a broad range of scientific and engineering challenges arising from the fact that, under terrestrial conditions, thermonuclear fuel must be surrounded by walls of a vacuum vessel. This applies to all confinement concepts considered for a fusion reactor: (a) inertial confinement based on the irradiation of a pellet with hydrogen isotopes by intense photon (laser) or ion beams; (b) plasma confined by strong magnetic field of the order a few tesla in devices called tokamaks (abbreviated from Russian "toroidal chamber with magnetic coils") or stellarators. This work deals with materials from tokamaks.

Over 80 experimental controlled fusion devices (CFDs) representing various plasma confinement concepts, magnetic and inertial, are active world-wide. The world's largest, operated with many modifications since June 1983, is the Joint European Torus (JET), a tokamak in the United Kingdom [1]. A next-step reactor-class device is under construction in France: ITER, meaning "The Way" in Latin. Lessons learnt from the construction and operation of earlier devices have been taken into account in the ITER design. It should be stressed that each tokamak or stellarator, operated either in the past or at present, has had specific scientific and technological missions. One of them is the test of plasma-facing materials (PFM) and components (PFC) to ensure reliable performance under extreme conditions of the nuclear environment [2-5].

Fusion processes considered for the reactor operation involve deuterium (D, d), tritium $(\mathrm{T}, \mathrm{t})$ and helium-3 $\left({ }^{3} \mathrm{He}\right)$ as substrates for reactions, while hydrogen (protium $\left.\mathrm{H}, \mathrm{p}\right),{ }^{4} \mathrm{He}$ (alpha particle) and neutrons are among products:

$$
\mathrm{D}+\mathrm{D} \rightarrow \mathrm{T}(1.01 \mathrm{MeV})+\mathrm{H}(3.03 \mathrm{MeV}),
$$




$$
\begin{gathered}
\mathrm{D}+\mathrm{D} \rightarrow{ }^{3} \mathrm{He}(0.82 \mathrm{MeV})+\mathrm{n}(2.45 \mathrm{MeV}), \\
\mathrm{D}+{ }^{3} \mathrm{He} \rightarrow \alpha(3.67 \mathrm{MeV})+\mathrm{H}(14.69 \mathrm{MeV}), \\
\mathrm{D}+\mathrm{T} \rightarrow \alpha(3.52 \mathrm{MeV})+\mathrm{n}(14.06 \mathrm{MeV}), \\
\mathrm{T}+\mathrm{T} \rightarrow{ }^{4} \mathrm{He}(3.77 \mathrm{MeV})+2 \mathrm{n}(7.53 \mathrm{MeV}) .
\end{gathered}
$$

The branching ratios of the reactions (1) and (2) are around one.

The main point in selecting a process for a reactor-class machine is the reaction rate and the availability or possibility of obtaining fuel. Present-day experimental magnetic CFDs use deuterium fuel, reactions (1) and (2), which is available in nature: around 34 $\mathrm{g}$ in $1 \mathrm{~m}^{3}$ of water. The practical use of Reaction 3 in reactor technology is not possible because of: (i) unavailability of ${ }^{3} \mathrm{He}$ in large quantities; and (ii) very high energy release ( $Q$ value) to which the wall materials would be exposed. That reaction, however, is very often used in ion beam analysis (IBA) of PFM, as addressed in Section 5. The comparison of cross-sections indicates the $\mathrm{D}-\mathrm{T}$ reaction as the most effective from the energy point of view. The maximum is around $70 \mathrm{keV}(700,000,000 \mathrm{~K})$ of D energy, but high D-T reactivity is reached already at $20 \mathrm{keV}$. Maxima of other reactions are above $120 \mathrm{keV}$ [6]. The D-T fusion results in the emission of a $3.5 \mathrm{MeV}$ alpha particle and a fast neutron carrying $14.1 \mathrm{MeV}$. The role of energetic alphas is to heat the plasma. This implies that PFC must eventually extract the radiated power, while the thermalized ${ }^{4} \mathrm{He}$ atoms are removed as ash during the fusion process. Neutrons pass PFM and interact with structural and functional materials of the reactor wall. Their energy is to be deposited in the lithium-containing blanket. Reactions with lithium produce tritium, which is indispensable for the reactor operation $[7,8]$. The role of neutrons and a neutron-induced effects have been described elsewhere $[9,10]$.

\section{Plasma-Wall Interactions and Wall Materials}

This work deals with the plasma impact on wall materials. They are modified by a set of processes known as plasma-material interactions (PMI) or plasma-wall interactions (PWI) [3,11-13]. The wall is irradiated by particles escaping the plasma: electrons; ions at different charge state; energetic neutrals; and neutrons. Some incoming particles are reflected, while others are implanted, thus changing the surface region composition. The implanted species may be: (i) released (desorbed) after certain time either in the original or chemically changed form, which-including the reflection-is called recycling; or (ii) trapped and reside in the solid either as a sole implant (e.g., interstitial) or chemically bound, which is known as retention. In either case, particles incoming from the plasma transfer a fraction of their energy to the wall material, causing its erosion. The main process is physical sputtering which occurs for all projectile-target combinations [14], unless the projectile energy is below the energy threshold for a given system [15]. The erosion is enhanced when the interaction involves chemical reaction(s) leading to the formation of volatile compounds with $\mathrm{H}$ isotopes $(\mathrm{H}, \mathrm{D}, \mathrm{T})$ or plasma impurities, e.g., $\mathrm{O}$ or $\mathrm{N}$. Other erosion channels are related to arcing and those caused by high heat loads resulting in cracking, melting, boiling, evaporation and splashing of the molten material.

All eroded and other (e.g., from leaks or intentionally seeded to the torus) plasma impurity atoms are instantly ionized and then travel along the magnetic field lines until they are pumped out or are redeposited in the torus at the place located close or far away from the place of origin. Upon re-deposition, plasma impurities are co-deposited together with $\mathrm{H}$ isotopes producing so-called co-deposits. Their properties are different from those characteristic for the original wall materials. Co-deposition is decisive for fuel inventory which must be strictly controlled; the in-vessel T retention in ITER is limited to $700 \mathrm{~g}[16,17]$. The formation of co-deposits has a major impact on all surface properties of PFC and, also, on in-vessel plasma diagnostic components. In addition, disintegration or exfoliation of co-deposits generates dust $[18,19]$. Fuel inventory and dust formation are crucial for the safety and economy in the D-T reactor operation. 
The list of required PFM properties comprises of: high thermal conductivity; resilience to thermal shocks; compatibility with vacuum; high melting point; low activation by neutrons; low reactivity with $\mathrm{H}$ isotopes; $\mathrm{O}, \mathrm{N}$ towards formation of volatile products; low sorption of $\mathrm{H}$ isotopes to minimize in-bulk fuel retention; low sputter erosion yield. There is no ideal material fulfilling such requirements. The search for a suitable material started in the late 1960s when the detrimental effects of PWI on plasma performance had been recognized. When saying "detrimental", one has to stress simultaneously that PWI processes are-first of all-unavoidable because plasma surrounding by the wall is a prerequisite. They are also necessary to thermalize and remove $\mathrm{He}$, and to extract neutron energy in the reactor blanket with Li compounds.

Over the years, a large variety of materials have been considered and tested as candidates, but eventually only a few of them have been used for wall components under a fusion environment. The status of wall materials in fusion devices until the end of the 20th century has been summarized in [3] The focus has been on carbon (C) in the form of graphite or various carbon fibre composites (CFC), tungsten (W) and beryllium (Be). For many years carbon was the main wall material in most devices [3,13,20-23]. Its power-handling capabilities are excellent, but its affinity to hydrogen isotopes results in chemical erosion (hydrocarbons) and, as a consequence, formation of co-deposited layers with unacceptable fuel inventory $[17,20,24-26]$. The original ITER plan was to use all three materials in various regions of the reactor dependent on the power load. However, such a material combination had never been tested together under fusion conditions. A large-scale test of the all-metal wall was decided in 2004: ITER-Like Wall Project at the JET tokamak (JET-ILW) [5]. Carbon components (JET-C; operated till October 2009) were replaced by Be on the main chamber wall and $W$ in the divertor [5,27]. A combined image in Figure 1 shows components of JET-C (left) and JET-ILW (right). The image also reveals the complexity of the plasma-facing wall with several types of limiters in the main chamber and the arrangement of tiles in the divertor. Details about respective structures can be found in [28] for JET-C and in [29-33] for the JET-ILW Project which involved a very broad R\&D (Research and Development) programme. The operation, started in 2011, indicated a significant decrease of fuel retention [34-36]. This was followed by the decision of the ITER Organisation to abandon carbon PFC, i.e., to use only $W$ in the divertor and Be in the main chamber [37].

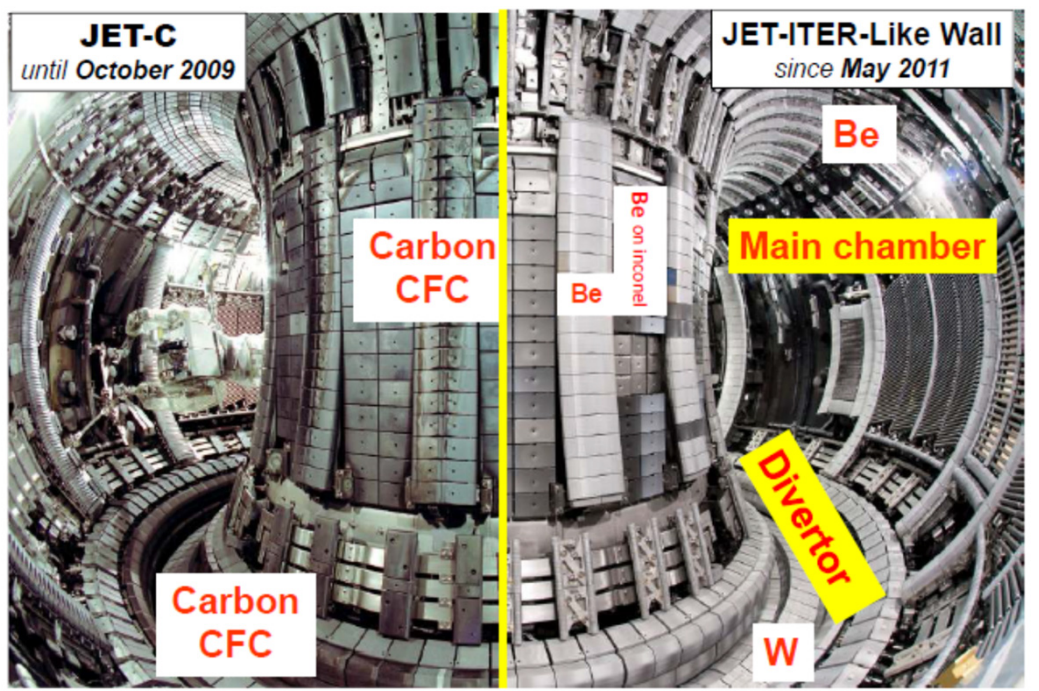

Figure 1. Toroidal view into the vacuum vessel of the Joint European Torus (JET) tokamak. Left: carbon fibre composites (CFC) limiter and divertor tiles in carbon components (JET-C). Right: ITERLike Wall (JET-ILW) with bulk Be limiters and Be-coated Inconel of the inner wall cladding in the main chamber and bulk W in the divertor base and W-coated CFC tiles in the inner and outer divertor legs. For details about wall materials in JET-ILW, see [5]. 


\section{The Role of Analysis in Studies of Reactor Materials}

Research in the field of PWI comprises three fundamental elements: (i) experiments in CFD and in relevant PWI simulators, which includes material testing; (ii) ex-situ and in-situ analysis of wall components and erosion-deposition probes, also called wall probes; and (iii) modelling. Therefore, analysis is not an isolated activity but an integral part of the entire research program. Its main role is to help understanding processes which modify materials, lead to the degradation of their properties, and to the contamination of fusion plasmas by species eroded from the wall. The analysis must provide data for the assessment of erosion-deposition pattern in the entire vessel and, thorough this, for modelling of material transport. To answer fundamental questions on what has happened and why in order to plan how to deal with a given problem, one has to possess knowledge on specific points regarding material migration, i.e., the location of erosion and deposition zones, the level of fuel inventory and the PWI impact on plasma diagnostic components. The study requires both (i) materials retrieved from the torus (a properly selected set of PFC tiles, wall probes and dust particles) and (ii) laboratories with specialized apparatus and capabilities of handling reactor materials contaminated for instance by Be and T [38].

\subsection{Species to Be Analysed}

The overall aim is to obtain a comprehensive overview of material migration. For that reason, analyses are carried out for all types of species present in the torus including those which were either deliberately or accidently introduced to the torus. The basic list starts with the hydrogen isotopes $(\mathrm{H}, \mathrm{D}, \mathrm{T})$ and ${ }^{4} \mathrm{He}, \mathrm{Be}, \mathrm{C}, \mathrm{O}$ impurity, then steel or Inconel ${ }^{\circledR}$ (or both) constituents of the vacuum vessel material ( $\mathrm{Fe}, \mathrm{Cr}, \mathrm{Ni}, \mathrm{Mn}, \mathrm{Mo}$ ) and finishes with tungsten. In practice, the number of species of interest is much longer, because one has to determine gases injected to the torus for plasma edge cooling (N, Ne, Ar, $\mathrm{Kr}$, $\mathrm{Xe})$, auxiliary heating with radio frequency $\left({ }^{3} \mathrm{He}\right.$ injected as minority species), tracers in material migration studies $\left({ }^{10} \mathrm{Be},{ }^{10} \mathrm{~B},{ }^{11} \mathrm{~B},{ }^{13} \mathrm{C},{ }^{15} \mathrm{~N},{ }^{18} \mathrm{O},{ }^{21} \mathrm{Ne}\right.$ and $\mathrm{F}$ in the form as Mo or $\mathrm{W}$ hexafluorides), elements for wall conditioning ( $\mathrm{Li}, \mathrm{B}, \mathrm{Si})$ and others used, for instance in marker tiles $(\mathrm{Ta}, \mathrm{Re})$.

\subsection{Tiles: Limiters and Divertor}

Figure 2 shows a number of wall tiles retrieved from the JET and Torus Experiment for Technology Oriented Research (TEXTOR, in operation in 1982-2013) tokamaks after long-term experimental campaigns. This collection demonstrates both the variety of shape, size and weight of components as well as surface characteristics after the exposure to plasma. All these features have a serious impact on the analytical procedure. Colourful patterns prove not uniform surface composition, attributed to erosion-deposition processes. Therefore, there is a need for mapping the distribution of various species over large surfaces. This calls for analysis stations with large chambers and manipulators with a long-travel distance to avoid sectioning of tiles, unless cutting or cleaving is necessary either for other studies (metallography, microscopy) or to reduce the level of activity to be handled in the case of samples containing for instance high amounts of tritium $[25,26,38]$. 


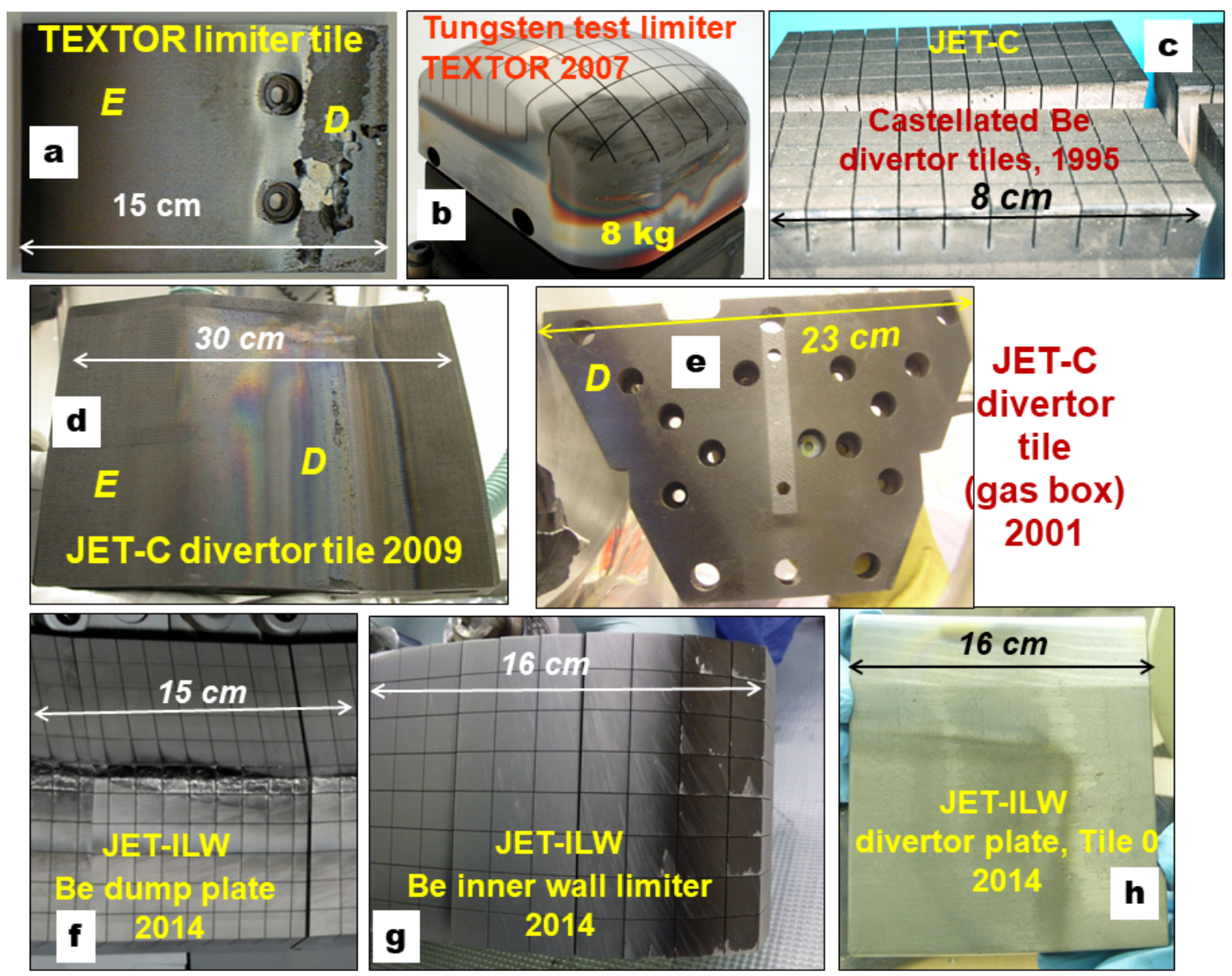

Figure 2. Plasma-facing components from TEXTOR and JET tokamaks: (a) graphite plate from the toroidal belt pump limiter; (b) castellated test limiter made of bulk W; (c) castellated Be tiles from Mk-I-Be divertor; (d) CFC tile from Mk-II divertor; (e) CFC tile from the septum structure of the Mk-II Gas Box divertor; (f) castellated upper dump plate (upper divertor) made of bulk Be; (g) castellated tile of the inner wall guard limiter made of bulk Be; (h) W-coated CFC tile from the upper part of the inner divertor. " $\mathrm{E}$ " and " $\mathrm{D}$ " denote erosion and deposition zones, respectively, on the corresponding plasma-facing components (PFC).

\section{Analysis Methods}

Nearly 50 different techniques have been applied to obtain the most fundamental and very specific information on the change of PFM/PFC morphology under the plasma impact: structure (surface and bulk) and composition (elemental, isotopic, chemical). There is no single method capable of addressing all these points. The most efficient set of tools is to be selected, i.e., methods for sensitive and selective determination of the content and distribution (lateral and in-depth) of hydrogen isotopes and several light and heavier elements listed in Section 3.1. Earlier reviews on techniques can be found in $[39,40]$. High speed in analysis is also important when probing hundreds of points over large areas of PFC. Such criteria are met by ion beam analysis (IBA) methods, especially accelerator-based techniques [39-43]. The principle of IBA is the irradiation of a solid with a monochromatic collimated ion beam followed by energy or mass analysis (or both) of species leaving the target. This is exemplified in Figure 3, showing the emission of different signals under ion irradiations: sputtered ions and neutrals (monoatomic or molecular); scattered primary ions; recoiled particles; photons originating from electronic and nuclear excitations; and a variety of nuclear reaction products including neutrons. Taking into account a broad energy range (a few $\mathrm{eV}$ to tens of $\mathrm{MeV}$ ) and various types of the primary beam (e.g., $\mathrm{H}^{+}$, $\left.\mathrm{D}^{+},{ }^{3} \mathrm{He}^{+},{ }^{4} \mathrm{He}^{+},{ }^{12} \mathrm{C}^{3+},{ }^{127} \mathrm{I}^{9+}\right)$ the number of combinations is huge. 


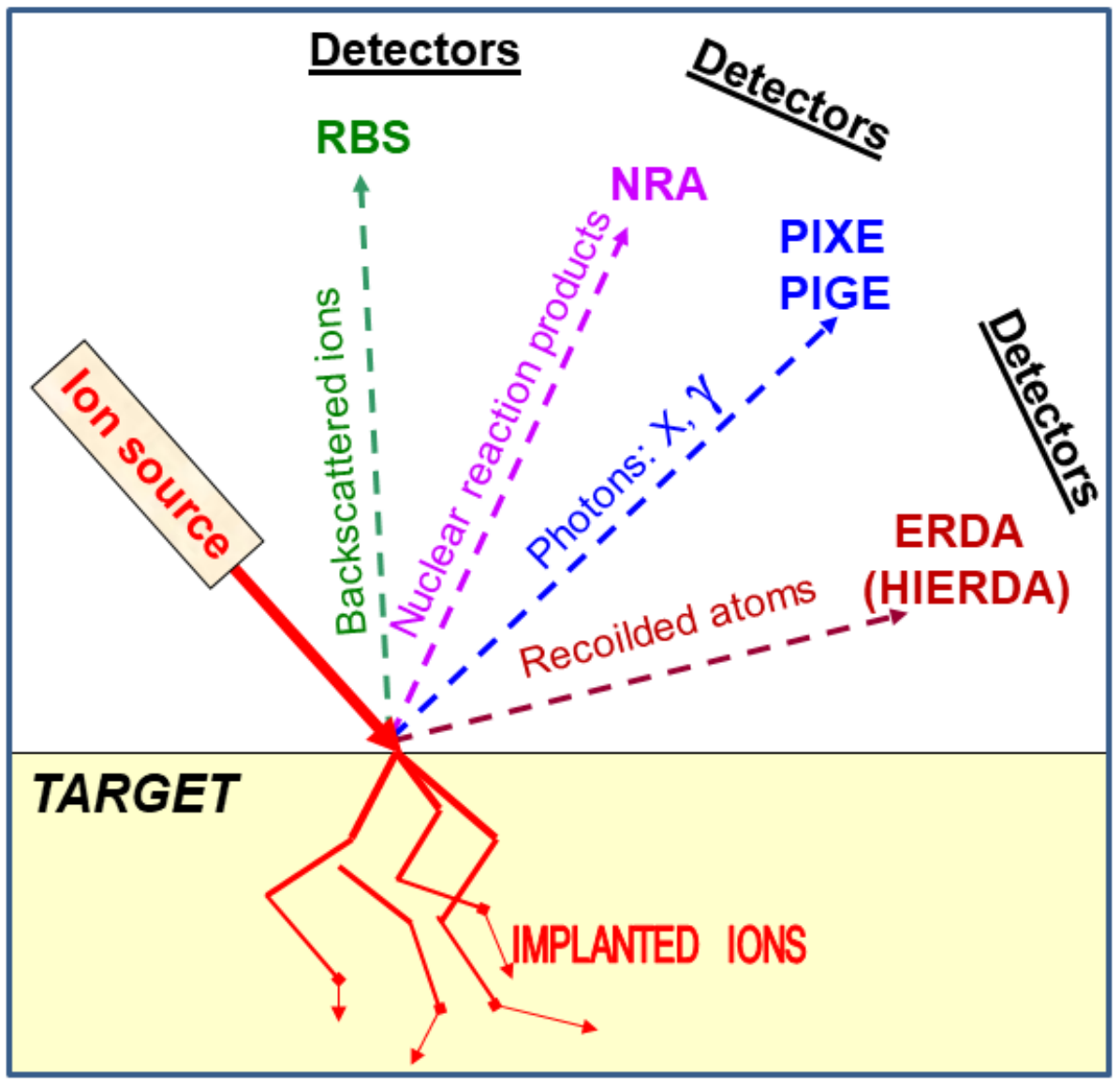

Figure 3. Ion-surface interactions: phenomena underlying different analysis methods. See text for details.

The palette of accelerator-based IBA for practical use in studies of reactor materials comprises Rutherford backscattering spectroscopy (RBS), particle induced X-ray emission (PIXE) and nuclear reaction analysis (NRA) both with a standard beam (diameter 0.6-1 mm) or micro-beam ( $\mu$-RBS, $\mu$-NRA, $\mu$-PIXE with lateral resolution in the range 0.5-20 $\mu \mathrm{m}$ ). It is stressed that NRA offers a large number of reactions to ensure proper selectivity in the detection of respective low- $Z$ isotopes. Such analyses are also carried out by means of time-of-flight high-energy elastic recoil detection (ToF-HIERDA) and accelerator mass spectrometry (AMS). Research capabilities are enhanced by new developments of apparatus and codes. For instance, deuterium retention studies have been extended by using high energy ${ }^{3} \mathrm{He}$ (up to $6 \mathrm{MeV}$ ) [44], a dedicated chamber has been constructed to enable in-situ studies of dynamic processes [45], while a new detection system has led to the improved mass resolution [46]. There are continuous updates of the SIM-NRA (SIMulation NRA) code for spectra analysis [47]. A comprehensive account on IBA facilities for studies of PFC is in [43]. A number of examples, especially in fuel retention studies, will be presented below.

\section{Fuel Retention Studies}

As mentioned in Sections 2 and 3, the determination of hydrogen isotopes in PFC is a top priority. It is motivated by the need to assess the inventory in a D-T reactor. Studies are concentrated on deuterium, i.e., the main fuel of present-day devices. The Application of NRA based on a ${ }^{3} \mathrm{He}^{+}$beam is the most efficient approach to determine $\mathrm{D}$ together with other low- $Z$ species such as $B$ and $C$ by detecting the energy spectrum of protons emerging from the following reactions: $\mathrm{d}\left({ }^{3} \mathrm{He}, \mathrm{p}\right) \alpha ;{ }^{9} \mathrm{Be}\left({ }^{3} \mathrm{He}, \mathrm{p}\right){ }^{11} \mathrm{~B}$; and ${ }^{12} \mathrm{C}\left({ }^{3} \mathrm{He}, \mathrm{p}\right){ }^{14} \mathrm{~N}$. A spectrum obtained with a $2.5 \mathrm{MeV}^{3} \mathrm{He}^{+}$beam is shown in Figure 4. In addition to protons from the above listed reactions there is also a feature associated with the ${ }^{13} \mathrm{C}\left({ }^{3} \mathrm{He}, \mathrm{p}\right){ }^{15} \mathrm{~N}$ reaction. 


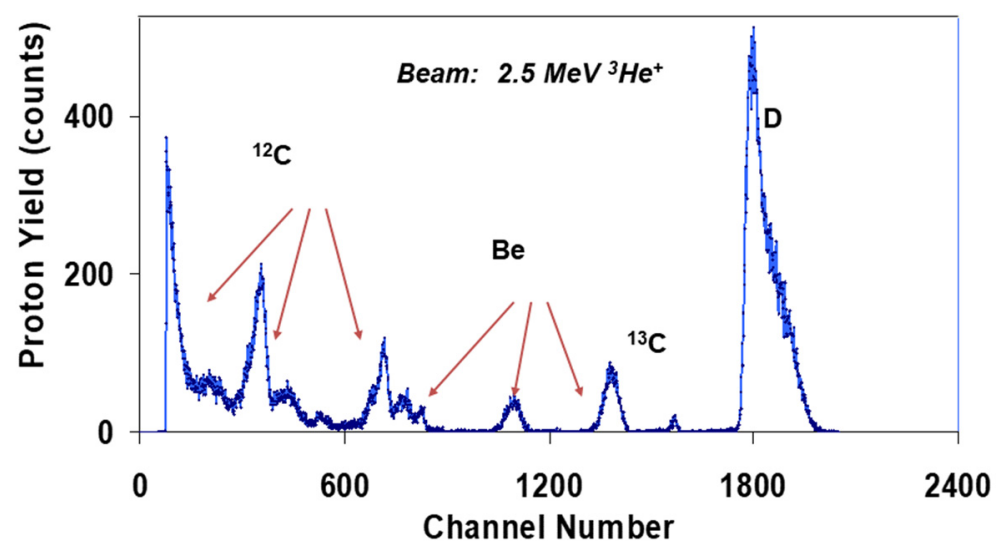

Figure 4. ${ }^{3} \mathrm{He}-\mathrm{NRA}$ spectrum for a divertor tile from JET-C showing features of carbon $\left({ }^{12} \mathrm{C}\right.$ and $\left.{ }^{13} \mathrm{C}\right)$, Be and D.

The analysis was carried out on a divertor tile from JET-C after material migration experiments employing a ${ }^{13} \mathrm{C}$-labeled methane $\left({ }^{13} \mathrm{CH}_{4}\right)$ as a tracer to determine the carbon transport to so-called remote areas [28,48,49]. These are regions outside the direct plasma line-of-sight, for instance shadowed areas in the inner and outer divertor.

Very detailed D analyses performed on material retrieved from JET-ILW, both PFC and wall probes from shadowed regions in the divertor, have consistently shown the decrease of retention by a factor of 10-15 in comparison to the situation in JET-C [50-58]. As well as this, the co-deposit thickness was decreased when the direct carbon source on PFC was eliminated. For instance, the thickness of co-deposits on wall probes (test mirrors) from the inner divertor after a full experimental campaign ( $20 \mathrm{~h}$ of plasma operation) dropped from around $20 \mu \mathrm{m}$ in JET-C to less than $1 \mu \mathrm{m}$ in JET-ILW [58]. To obtain a more complete retention pattern in JET-ILW, two analyses were performed: (i) inside the grooves of castellated Be limiters (see Figure 2f-g); and (ii) on the Be-coated Inconel tiles of the inner wall cladding (for details see the right side of Figure 1).

All plasma-facing components in ITER will be castellated because such a structure of tiles is deemed to be the best solution to ensure thermo-mechanical durability and integrity of materials under high heat flux loads. However, $0.4 \mathrm{~mm}$ wide grooves of castellation may act as shadowed zones of PFC in which co-deposits rich in fuel can be formed. Therefore, side surfaces located in the grooves are to be studied. The motivation for studies of the JET castellated structures is related to the fact that nearly 2,000,000 such surfaces will be in ITER in the Be panels in the main chamber and in the $\mathrm{W}$ divertor. The analysis has been possible only after cutting the Be tiles using special procedures and applying $\mu$-NRA to determine the deposition pattern [59]. Figure 5a-c show, respectively, the surface inside the castellation, the geometry of the castellated block and the deposition profiles of $\mathrm{D}$ and trace quantities of metallic plasma impurities. The $\mathrm{D}$ presence is detected only in narrow deposition belts $0.5-1.3 \mathrm{~mm}$ deep into the gap. In most cases (around 100 studied surfaces) the D content was below $1 \times 10^{18} \mathrm{~cm}^{-2}$, and in no case did it exceed $3 \times 10^{18} \mathrm{~cm}^{-2}$. Such quantities are considered to be very small from the point of view of retention. However, Be limiters in JET have nearly 180,000 surfaces in the gaps ( $7.5 \mathrm{~km}$ long); thus, the impact on the total retention must be considered. The total $\mathrm{D}$ content has been estimated to be in the range of $0.7 \times 10^{22}$ to $14.2 \times 10^{22}$ in the castellation. The upper value is of a similar level as the retention determined reported in [50] on the PFC (CHANED; PLEASE CONFIRN) of the limiters, indicating that the deposition in the grooves of castellation is not decisive for the entire deuterium inventory; most $\mathrm{D}$ is retained in the divertor. However, the contribution from the castellation cannot be neglected in the total count. This issue will be carefully treated at ITER because of the in-vessel T limit of $700 \mathrm{~g}[16,17]$. 

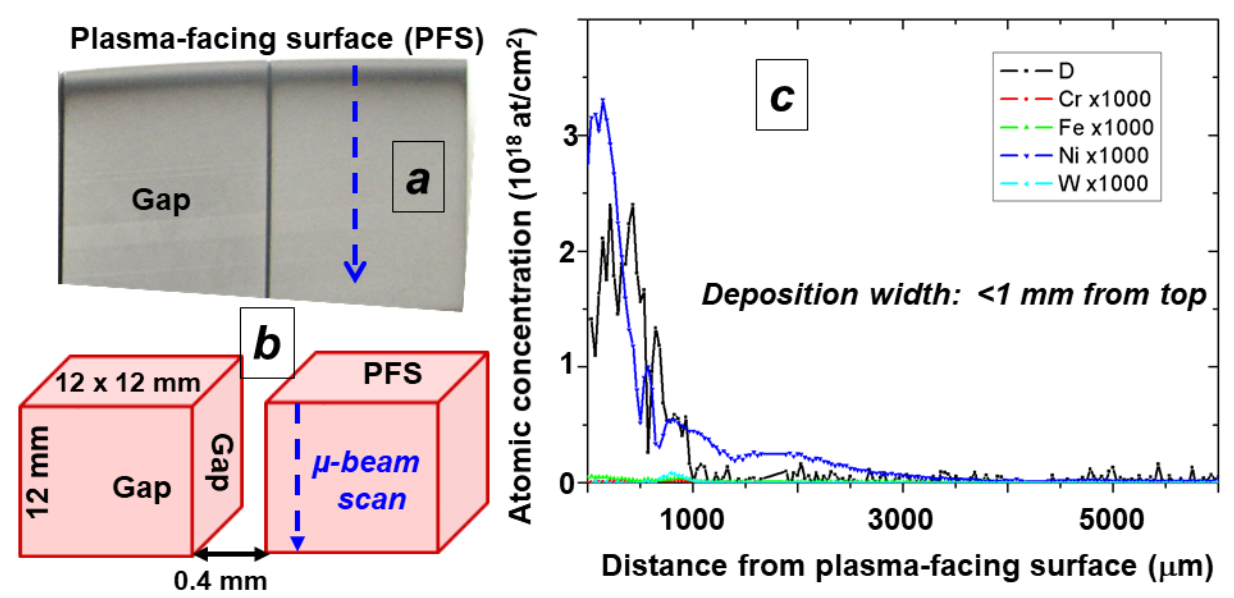

Figure 5. Deposition inside castellated Be limiters from JET-ILW: (a) side surface of the castellation with a narrow deposition belt at the entrance to the gap; (b) schematic view of a castellated structure; (c) deposition profiles of $\mathrm{D}$ and metals in the castellation; note the plotted metal contents are magnified by a factor of 1000 .

${ }^{3}$ He-based NRA is extremely efficient in D studies on PFC surfaces. However, the assessment of global inventory requires knowledge of all hydrogen isotopes. Protium, though not used as a regular fuel in JET, is of interest because of possible H-D isotope exchange especially if an experimental campaign is finished with hydrogen discharges in order to clean the wall. Development and availability of protium analyses methods is strongly motivated by the fact that in the first phase of CFD operation, $\mathrm{H}$ fueling is used to avoid the immediate activation of components: Wendelstein-7X stellarator [60], also planned in JT60-SA and ITER. Protium analysis with ${ }^{15} \mathrm{~N}(\mathrm{p}, \alpha, \gamma){ }^{12} \mathrm{C}$ is limited to a small depth of less than $1 \mu \mathrm{m}$ and, the quantification suffers from significant ion-induced detrapping of the analysed isotope. The aim is to measure $\mathrm{H}$ and $\mathrm{D}$ simultaneously within the same surface layer. Plots in Figure $6 \mathrm{a}-\mathrm{d}$ show ToF-HIERDA (42 MeV ${ }^{127} \mathrm{I}^{9+}$ beam) spectra and depth profiles recorded for the initial (Figure 6a,b) and exposed (Figure 6c,d) beryllium-coated Inconel $^{\circledR}$ tiles from the inner wall cladding of JET-ILW. The initial Be coating contains oxygen ( $10 \%$ at the very surface and $3-4 \%$ in depth) as the main impurity. Carbon and aluminum (Al source is unknown) are at the level of $1 \%$. In the exposed plate, one detects gettered oxygen (20-40\%) and co-deposited H, D, C, N. Hydrogen is clearly detected. Its content is greater than that of $\mathrm{D}$, because the campaign was finished with 300 discharges fueled with $\mathrm{H}[59,61,62]$.

Figure 7 shows results obtained with ToF-HIERDA for a co-deposit on a Si plate of a dust monitor located in JET-ILW above the outer divertor [18]. The plate was exposed during the second ILW campaign. Be is the main element in the co-deposit. There is also a significant amount of $\mathrm{Ni}$; its origin is explained in [63]. Other species are clearly marked in the spectrum thus proving simultaneous detection of light and heavy constituents from $\mathrm{H}$ to W. This makes ToF-HIERDA extremely useful in studies of wall probes from JET-ILW where the thickness of co-deposits does not exceed $1 \mu \mathrm{m}[57,58,64,65]$.

The overall objective of PFC analyses is to obtain a global pattern of material migration and fuel retention. The main factor, limiting the extent of studies, is the availability of a large number of wall tiles and probes. The access to such reservoir is possible only at the end-of-life of a given machine, i.e., at the decommissioning phase. This was the case of the TEXTOR tokamak when a large number of tiles from different limiters could be retrieved and examined [66-68]. After the decommissioning of TEXTOR, a large number of tiles was removed from different PFC surfaces, such as the so-called ALT-II limiter (Advanced Limiter Test II) which was the main plasma limiting component and hence of highest interest, and the inner bumper limiter (IBL) which was several centimeters away from the plasma but had the highest surface area of all limiters. The deuterium content was 
measured around both toroidal angular directions phi and theta on these components in order to draw a retention map of these PFCs: this can be seen in the toroidal belt limiter ALTII which was composed of eight blades, and an IBL acting as a shield of the ergodig dynamic divertor, as shown in Figure 8. NRA measurements were performed with a $2.8 \mathrm{MeV}^{3} \mathrm{He}^{+}$ beam enabling depth profiling to the depth of $10 \mu \mathrm{m}$. Numerical methods used for the interpolation play a crucial role in the insightful visualization of measurement results; they are explained in $[67,68]$. On most ALT-II limiter tiles the deuterium is retained within the first $1-2 \mu \mathrm{m}$, with maximum concentration around $4-6 \%$ of the material mixture. On the bumper limiter, the deuterium is depleted in the first $\mu \mathrm{m}$, peaks at ca. $2 \mu \mathrm{m}$, and falls off slowly with a measurable $\mathrm{D}$ content down to maximum $9 \mu \mathrm{m}$. The concentration maxima scatter between 2 and 12\% of the material mixture. In summary, these comprehensive analyses have shown that after the last experimental campaign of TEXTOR, the bumper limiter had the highest surface concentration of fuel with average value of $3.2 \times 10^{18} \mathrm{~cm}^{-2}$, while the average D content on ALT-II was at the level of $0.4 \times 10^{18} \mathrm{~cm}^{-2}$.
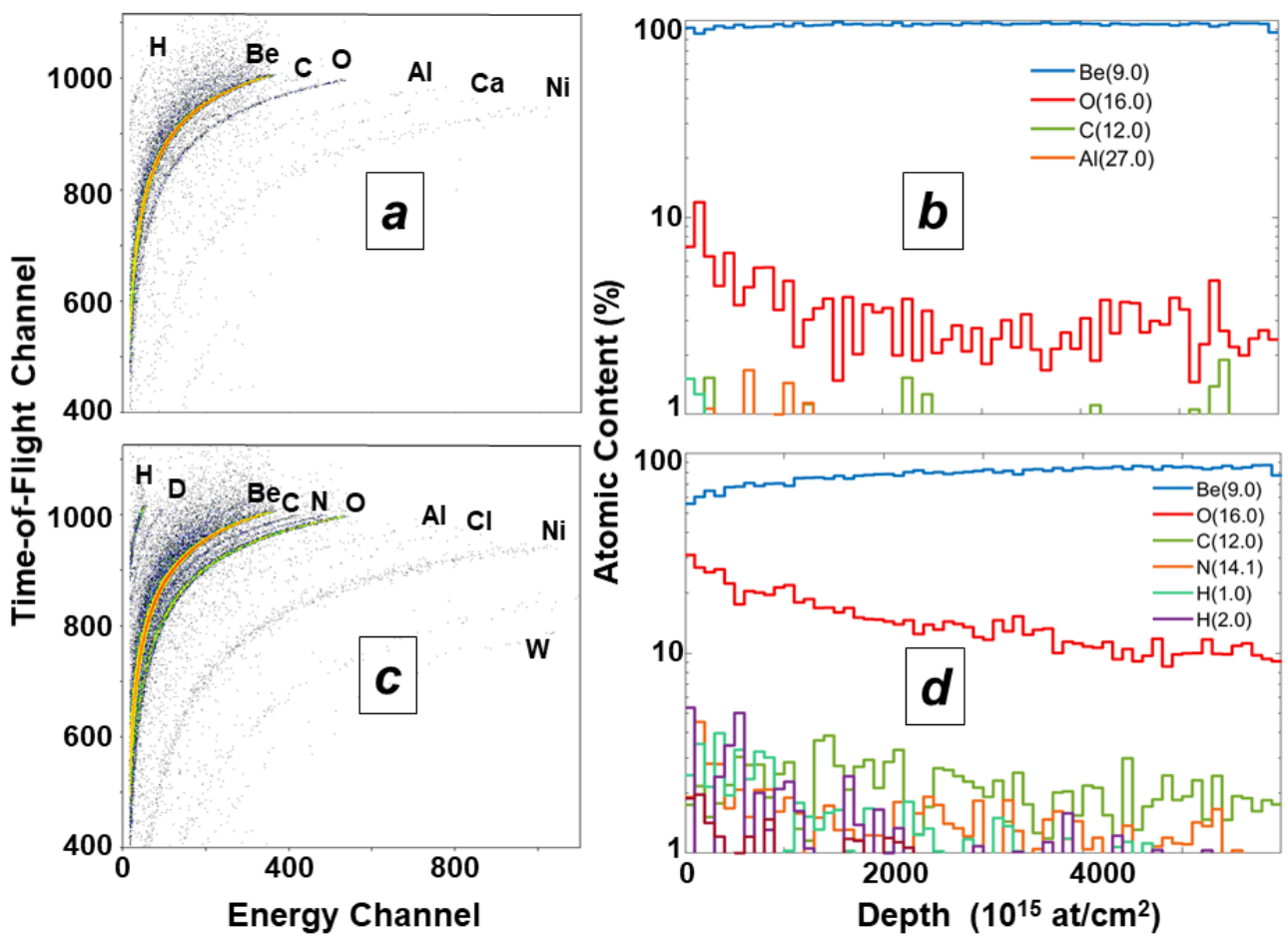

Figure 6. ToF-HIERDA spectra $(\mathbf{a}, \mathbf{c})$ and depth profiles $(\mathbf{b}, \mathbf{d})$ of species in the surface region of Be coatings from the inner wall cladding of JET-ILW for initial not exposed surfaces $(\mathbf{a}, \mathbf{b})$ and after exposure (c,d) during the first and second ILW campaign.
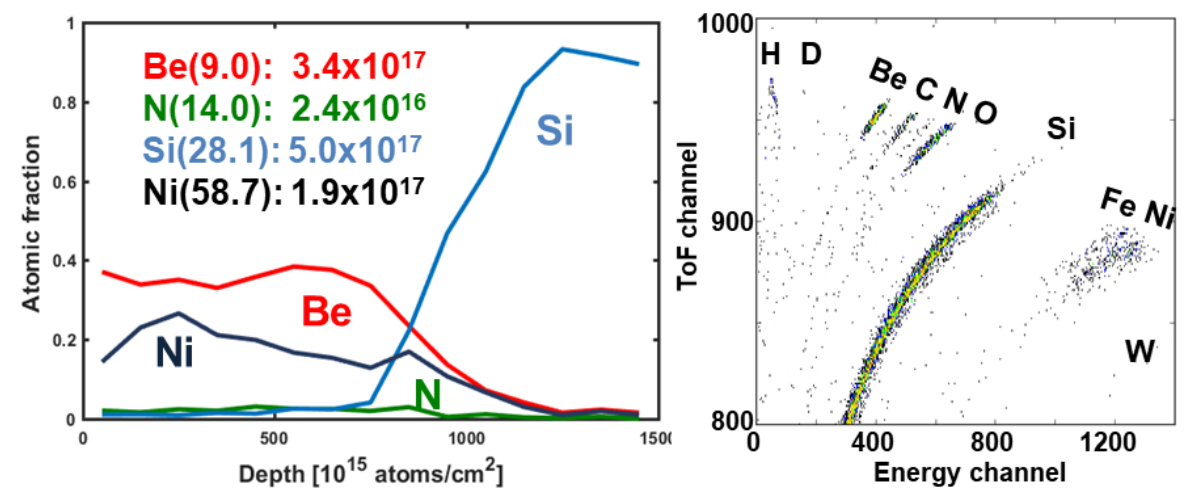

Figure 7. ToF-HIERDA depth profile and spectrum of co-deposit on the silicon plate of the dust monitor in JET-ILW. 


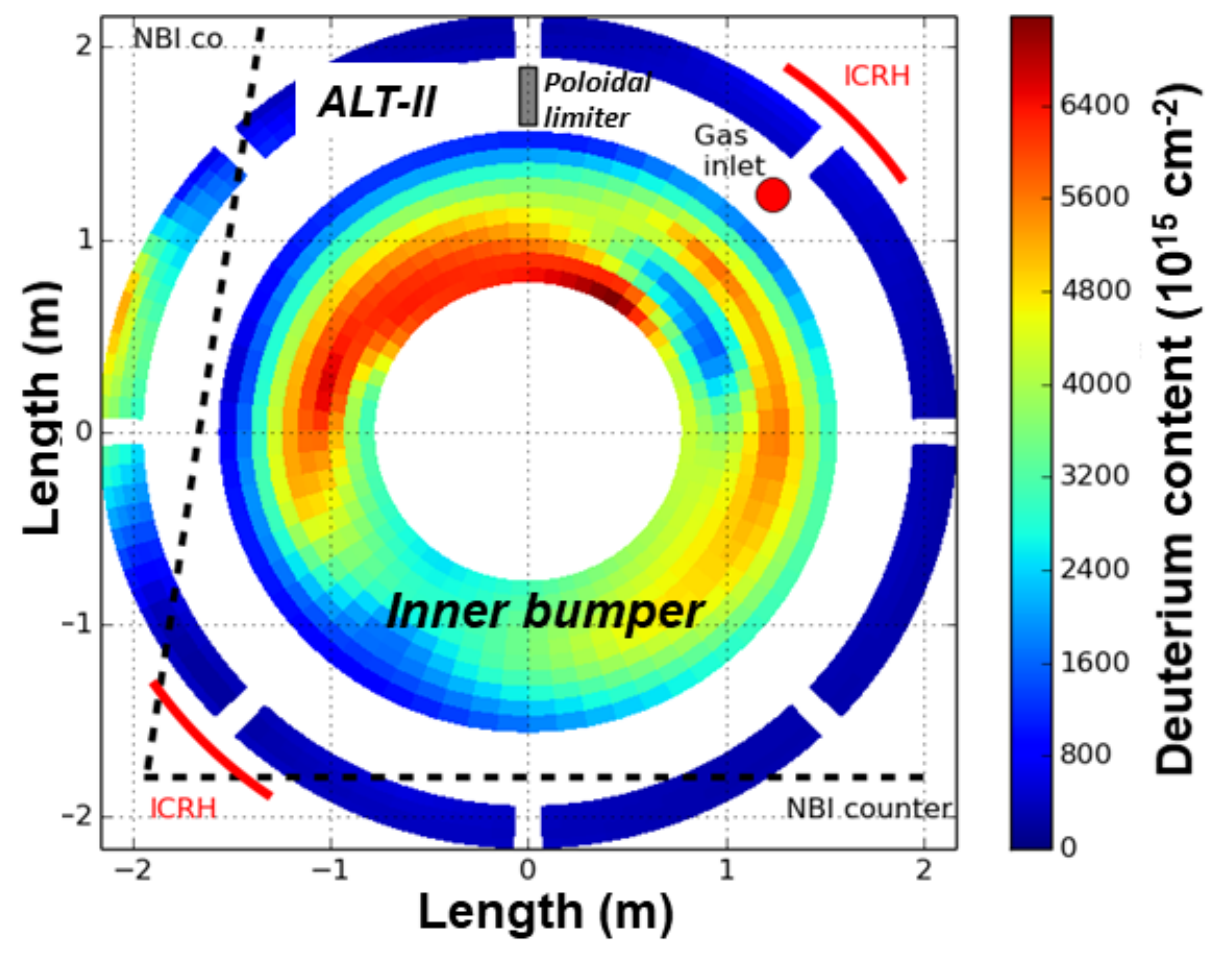

Figure 8. Mapping of the total deuterium content on the PFC of TEXTOR. "ICRH" stays for ion cyclotron resonance heating, "NBI" denotes neutral beam injection (co-injector and counter injector), and "ALT-II" stays for Advanced Limiter Test II.

\section{Ion-Induced Detrapping}

Ion-induced release (detrapping) of $\mathrm{H}$ isotopes by the high-energy analyzing beam is to be taken into account in the quantification of retained fuel $[26,64,69]$. Therefore, $\mathrm{D}$ analysis should be performed with a relatively small ${ }^{3} \mathrm{He}^{+}$dose $(0.2-1 \mu \mathrm{C})$, unless the detrapping process itself is studied. The effective cross-sections for detrapping depend on the layer structure and its chemical composition, i.e., hybridisation, content of various plasma impurities in co-deposits, etc., as discussed in [70]. The substrate temperature also plays a role in the layer growth.

Figure 9a shows the change in the $\mathrm{D}$ depth profile and content in a co-deposit irradiated with an increasing dose of the $1.5 \mathrm{MeV}^{3} \mathrm{He}^{+}$beam: $4.7 \times 10^{14} \mathrm{~cm}^{-2}(\mathrm{~A}) ; 23.4 \times 10^{15} \mathrm{~cm}^{-2}$ (B); and $46.8 \times 10^{15} \mathrm{~cm}^{-2}$ (C). The profiles are recorded for a co-deposit formed on a collector probe exposed to the edge plasma at TEXTOR during discharges heated by neutral beam injection. The depth profiles show a gradual but substantial release of $\mathrm{D}$ by over $45 \%$ from $2.6 \times 10^{18} \mathrm{~cm}^{-2}$ to $1.4 \times 10^{18} \mathrm{~cm}^{-2}$. The decrease is not uniform: over $50 \%$ is released from the deepest region of the deposit; $35 \%$ from the middle layer $(0.5-1.5 \mu \mathrm{m})$; and only about $5 \%$ from the surface region. The $\mathrm{D}$ release by $\mathrm{MeV}^{3} \mathrm{He}$ ions occurs mostly via electronic excitations. The effect is pronounced at the depth, where the ${ }^{3} \mathrm{He}^{+}$energy is deposited most effectively. As shown in Figure 9b, the electronic stopping power of $1.5 \mathrm{MeV}^{3} \mathrm{He}$ ions in carbon matrix increases with depth reaching its maximum between 3 and $4 \mu \mathrm{m}$, i.e., in the region where the most effective detrapping has occurred; this region is indicated by a red arrow in Figure $9 b$. 

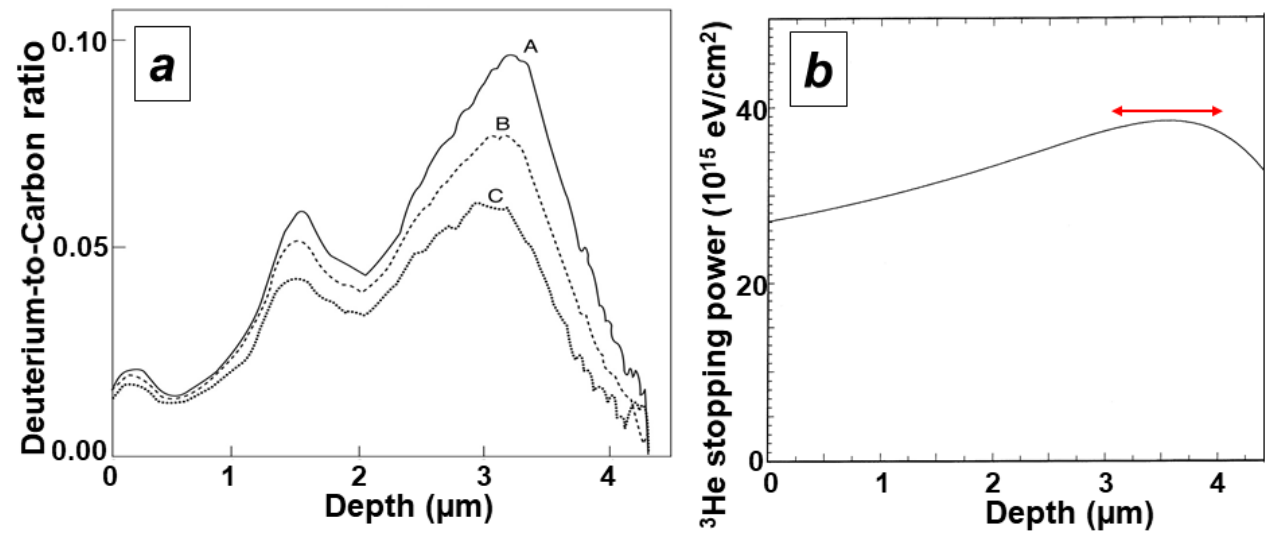

Figure 9. Ion-induced release of D from co-deposits studied with ${ }^{3} \mathrm{He}-\mathrm{NRA}$ : (a) the change of D depth profiles with the increased ion dose; " $\mathrm{A}$ ", " $\mathrm{B}$ " and " $\mathrm{C}$ " denote different co-deposit irradiation dose curves; (b) ${ }^{3} \mathrm{He}$ electronic stopping in a carbon target; the red arrow indicates the most effective detrapping region.

\section{Summary}

In a brief synopsis, as presented above, only some topics and applications of IBA in studies of fusion reactor materials could be addressed. The methods, all with inherent advantages and also serious limitations, provide the most effective toolbox in PFC analyses from present-day devices. To meet contemporary research requirements, continuous development of analytical tools takes place both at academic institutions and specialised industrial companies. In turn, such advances widen experimental capabilities, especially in material migration studies (use of tracers) and in laboratory-based research under controlled conditions, e.g., interaction between hydrogen and candidates for wall materials. The latter involves chambers for in-situ experiments (e.g., exposure to plasma, implantation, thermal treatment) with simultaneous analyses to determine the dynamics of processes without breaking vacuum; the research challenges have been addressed in [45]. In-situ IBA, i.e., inside a fusion device, has been discussed for a long time and, once, it has been demonstrated in Alcator-C Mod [71]. However, such an approach in a reactor-class machine will not be possible. IBA techniques play a crucial role in the preparation and calibration of laser-based in-situ diagnosis of fuel retention [72], and they will be essential in PFC analyses after deuterium-tritium campaigns.

Author Contributions: All authors took part in IBA measurements (material analysis) and data analysis, discussions and formulation of conclusions. All authors have read and agreed to the published version of the manuscript.

Funding: This work was carried out within the framework of the EUROfusion consortium and has received funding from the Euratom research and training programme 2014-2018 and 2019-2020 under Grant Agreement No. 633053. The work has been supported by the Swedish Research Council (VR), Grant 2015-04844. Financial support of the Tandem Accelerator Infrastructure by VR-RFI (contract \#2017-00646_9) as well as the Swedish Foundation for Strategic Research (SSF) under contract RIF14-0053 is gratefully acknowledged.

Data Availability Statement: Not applicable.

Acknowledgments: The authors wish to acknowledge the JET Contributors (J. Mailloux, 28th IAEA Fusion Energy Conference 2020, Vienna, Austria, 10-15 May 2021).

Conflicts of Interest: The authors declere no conflict of interest.

\section{References}

1. Litaudon, X.; Abduallev, S.; Abhangi, M.; Abreu, P.; Afzal, M.; Aggarwal, K.; Ahlgren, T.; Ahn, J.; Aho-Mantila, L.; Aiba, N.; et al. Overview of the JET in support of ITER. Nucl. Fusion 2017, 57, 102001. [CrossRef] 
2. Loarte, A.; Lipschultz, B.; Kukushkin, A.; Matthews, G.; Stangeby, P.; Asakura, N.; Counsell, G.; Federici, G.; Kallenbach, A.; Krieger, K.; et al. Power and particle control. Nucl. Fusion 2007, 47, S203-S263. [CrossRef]

3. Federici, G.; Skinner, C.; Brooks, J.; Coad, J.; Grisolia, C.; Haasz, A.; Hassanein, A.; Philipps, V.; Pitcher, C.; Roth, J.; et al Plasma-material interactions in current tokamaks and their implications for next step fusion reactors. Nucl. Fusion 2001, 41, 1967-2137. [CrossRef]

4. Linke, J. Plasma facing materials and components for future fusion devices-Development, characterization and performance under fusion specific loading conditions. Phys. Scr. 2006, T123, 45-53. [CrossRef]

5. Matthews, G.F.; Edwards, P.; Hirai, T.; Kear, M.; Lioure, A.; Lomas, P.; Loving, A.; Lungu, C.; Maier, H.; Mertens, P.; et al. ITER-like wall project overview. Phys. Scr. 2007, T128, 137-143. [CrossRef]

6. Bosch, H.-S.; Halle, G.M. Improved formulas for fusion cross-sections and thermal reactivities. Nucl. Fusion 1992, 32, 611-632. [CrossRef]

7. Tanabe, T. (Ed.) Tritium: Fuel of Fusion Reactors; Springer: Tokyo, Japan, 2017. [CrossRef]

8. Rubel, M. Fusion neutrons: Tritium breeding and impact on wall materials and components of diagnostic systems. J. Fusion Energy 2019, 38, 315-329. [CrossRef]

9. Baluc, N. Materials for fusion power reactors. Plasma Phys. Control. Fusion 2006, 48, B165-B178. [CrossRef]

10. Neustroev, V.S.; Garner, F.A. Severe embrittlement of neutron irradiated austenitic steels arising from high void swelling. J. Nucl. Mater. 2009, 386-388, 157-160. [CrossRef]

11. Naujoks, D. Plasma-Material Interactions in Controlled Fusion; Springer: Berlin/Heidelberg, Germany, 2006. [CrossRef]

12. Hofer, W.O.; Roth, J. (Eds.) Physical Processes of the Interaction of Fusion Plasmas with Solids; Academic Press: San Diego, CA, USA, 1996.

13. Philipps, V.; Wienhold, P.; Kirschner, A.; Rubel, M. Erosion and redeposition of wall material in controlled fusion devices. Vacuum 2002, 67, 399-408. [CrossRef]

14. Behrisch, R. (Ed.) Sputtering by Particle Bombardment; Springer: Berlin/Heidelberg, Germany, 1981.

15. Roth, J.; Tsitrone, E.; Loarer, T.; Philipps, V.; Brezinsek, S.; Loarte, A.; Counsell, G.F.; Doerner, R.P.; Schmid, K.; Ogorodnikova, O.V.; et al. Tritium inventory in ITER plasma-facing materials and tritium removal procedures. Plasma Phys. Control. Fusion 2008, 50, 103001. [CrossRef]

16. Roth, J.; Tsitrone, E.; Loarte, A.; Loarer, T.; Counsell, G.; Neu, R.; Philipps, V.; Brezinsek, S.; Lehnen, M.; Coad, P.; et al. Recent analysis of key plasma-wall interaction parameters for ITER. J. Nucl. Mater. 2009, 390-391, 1-9. [CrossRef]

17. Counsell, G.C.; Coad, P.; Grisola, C.; Hopf, C.; Jacob, W.; Kirschner, A.; Kreter, A.; Krieger, K.; Likonen, J.; Philipps, V.; et al. Tritium retention in next step devices and the requirements for mitigation and removal techniques. Plasma Phys. Control. Fusion 2006, 48, B189-B199. [CrossRef]

18. Rubel, M.; Widdowson, A.; Grzonka, J.; Fortuna-Zalesna, E.; Moon, S.; Petersson, P.; Ashikawa, N.; Asakura, N.; Hamaguchi, D.; Hatano, Y.; et al. Dust generation in tokamaks: Overview of beryllium and tungsten dust characterisation in JET with the ITER-like wall. Fusion Eng. Des. 2018, 136, 579-586. [CrossRef]

19. Otsuka, T.; Masuzaki, S.; Ashikawa, N.; Hatano, Y.; Asakura, Y.; Suzuki, T.; Suzuki, T.; Isobe, K.; Hayashi, T.; Tokitani, M.; et al Tritium retention characteristics in dust particles in JET with ITER-like wall. Nucl. Mater. Energy 2018, 17, 279-286. [CrossRef]

20. Coad, J.P.; Bekris, N.; Elder, J.; Erents, S.; Hole, D.; Lawson, K.; Matthews, G.; Penzhorn, R.-D.; Stangeby, P. Erosion/deposition issues in JET. J. Nucl. Mater. 2001, 290-293, 224-230. [CrossRef]

21. Tsitrone, E.; Pégourié, B.; Marandet, Y.; Artaud, J.; Brosset, C.; Bucalossi, J.; Corre, Y.; Dittmar, T.; Gauthier, E.; Languille, P.; et al Multi machine scaling of fuel retention in 4 carbon dominated tokamaks. J. Nucl. Mater. 2011, 415, S735-S739. [CrossRef]

22. Skinner, C.; Gentile, C.; Hosea, J.; Mueller, D.; Coad, J.; Federici, G.; Haange, R. Tritium experience in large tokamaks: Application to ITER. Nucl. Fusion 1999, 39, 271-292. [CrossRef]

23. Allen, S.; Wampler, W.; McLean, A.; Whyte, D.; West, W.; Stangeby, P.; Brooks, N.; Rudakov, D.; Phillips, V.; Rubel, M.; et al. ${ }^{13} \mathrm{C}$ transport studies in L-mode divertor plasmas on DIII-D. J. Nucl. Mater. 2005, 337-339, 30-34. [CrossRef]

24. Loarer, T.; Brosset, C.; Bucalossi, J.; Coad, P.; Esser, G.; Hogan, J.; Likonen, J.; Mayer, M.; Morgan, P.; Philipps, V.; et al. Gas balance and fuel retention in fusion devices. Nucl. Fusion 2007, 47, 1112-1120. [CrossRef]

25. Penzhorn, R.-D.; Bekris, N.; Berndt, U.; Coad, J.; Ziegler, H.; Nägele, W. Tritium depth profiles in graphite and carbon fibre composite material exposed to tokamak plasmas. J. Nucl. Mater. 2001, 288, 170-178. [CrossRef]

26. Rubel, M.; Coad, J.; Bekris, N.; Erents, S.; Hole, D.; Matthews, G.; Penzhorn, R.-D. Beryllium and carbon films in JET following D-T operation. J. Nucl. Mater. 2003, 313-316, 321-326. [CrossRef]

27. Matthews, G.F.; Beurskens, M.; Brezinsek, S.; Groth, M.; Joffrin, E.; Loving, A.; Kear, M.; Mayoral, M.-L.; Neu, R.; Prior, P.; et al JET ITER-like wall-Overview and experimental program. Phys. Scr. 2011, T145, 014001. [CrossRef]

28. Coad, J.P.; Rubel, M.; Likonen, J.; Bekris, N.; Brezinsek, S.; Matthews, G.; Mayer, M.; Widdowson, A. Material migration and fuel retention studies during the JET carbon divertor campaigns. Fusion Engin. Des. 2018, 138, 78-108. [CrossRef]

29. Maier, H.; Hirai, T.; Rubel, M.; Neu, R.; Mertens, P.; Greuner, H.; Hopf, C.; Matthews, G.; Neubauer, O.; Piazza, G.; et al. Tungsten and beryllium armour development for the JET ITER-like wall project. Nucl. Fusion 2007, 47, 222-227. [CrossRef]

30. Rubel, M.; Bailescu, V.; Coad, J.P.; Hirai, T.; Likonen, J.; Linke, J.; Lungu, C.P.; Matthews, G.F.; Pedrick, L.; Riccardo, V.; et al. Beryllium plasma-facing components for the ITER-like wall project at JET. J. Phys. Conf. Ser. 2008, 100, 062028. [CrossRef] 
31. Mertens, P.; Philipps, V.; Pintsuk, G.; Riccardo, V.; Samm, U.; Thompson, V.; Uytdenhouwen, I. Clamping of solid tungsten components for the bulk W divertor row in JET-precautionary design for a brittle material. Phys. Scr. 2009, T138, 014032. [CrossRef]

32. Mertens, P. Detailed design of a solid tungsten divertor row for JET in relation to the physics goals. Phys. Scr. 2011, T145, 014002. [CrossRef]

33. Matthews, G.F.; Edwards, P.; Greuner, H.; Loving, A.; Maier, H.; Mertens, P.; Philipps, V.; Riccardo, V.; Rubel, M.; Ruset, C.; et al. Current status of the JET ITER-like wall project. Phys. Scr. 2010, T138, 014030. [CrossRef]

34. Matthews, G.F.; JET EFDA Contributors; ASDEX-Upgrade Team. Plasma operation with an all metal first-wall: Comparison of an ITER-like wall with a carbon wall in JET. J. Nucl. Mater. 2013, 438, S2-S10. [CrossRef]

35. Loarer, T.; Brezinsek, S.; Philipps, V.; Bucalossi, J.; Douai, D.; Esser, H.; Grunhagen, S.; Hobirk, J.; Jachmich, S.; Joffrin, E.; et al. Comparison of fuel retention in JET between carbon and the ITER-like wall. J. Nucl. Mater. 2013, 438, S108-S113. [CrossRef]

36. Brezinsek, S.; Widdowson, A.; Mayer, M.; Philipps, V.; Baron-Wiechec, A.; Coenen, J.W.; Heinola, K.; Huber, A.; Likonen, J.; Petersson, P.; et al. Beryllium migration in JET ITER-like wall plasmas. Nucl. Fusion 2015, 55, 063021. [CrossRef]

37. Merola, M.; Escourbiac, F.; Raffray, R.; Chappuis, P.; Hirai, T.; Martin, A. Overview and status of ITER internal components. Fusion Eng. Des. 2014, 89, 890-895. [CrossRef]

38. Widdowson, A.; Baron-Wiechec, A.; Batistoni, P.; Belonohy, E.; Coad, J.P.; Dinca, P.; Flammini, D.; Fox, F.; Heinola, K.; Jepu, I.; et al. Experience of handling beryllium, tritium and activated components from JET ITER like wall. Phys. Scr. 2016, T167, 014057. [CrossRef]

39. Rubel, M. Analysis of plasma facing materials: Material migration and fuel retention. Phys. Scr. 2006, T123, 54-65. [CrossRef]

40. Rubel, M.; Petersson, P.; Alves, E.; Brezinsek, S.; Coad, J.P.; Heinola, K.; Mayer, M.; Widdowson, A. The role and application of ion beam analysis for studies of plasma-facing components in controlled fusion devices. Nucl. Instr. Meth. 2016, B371, 4-11. [CrossRef]

41. Chu, W.K.; Mayer, M.; Nicolet, M.A. Backscattering Spectroscopy; Academic Press: New York, NY, USA, 1978.

42. Tesmer, J.R.; Nastasi, M. (Eds.) Handbook of Modern Ion Beam Analysis; Material Research Society: Pittsburg, PA, USA, 1995.

43. Mayer, M.; Möller, S.; Rubel, M.; Widdowson, A.; Charisopoulos, S.; Ahlgren, T.; Alves, E.; Apostolopoulos, G.; Barradas, N.P.; E Donnelly, S.; et al. Ion beam analysis of fusion plasma-facing materials and components: Facilities and research challenges. Nucl. Fusion 2020, 60, 025001. [CrossRef]

44. Mayer, M.; Gauthier, E.; Sugiyama, K.; von Toussaint, U. Quantitative depth profiling of deuterium up to very large depths. Nucl. Instr. Meth. 2009, B267, 506-512. [CrossRef]

45. Kantre, K.; Szabo, P.S.; Moro, M.V.; Cupak, C.; Stadlmayr, R.; Medina, L.Z.; Aumayr, F.; Primetzhofer, D. Combination of in-situ ion beam analysis and thermal desorption spectroscopy for studying deuterium implanted in tungsten. Phys. Scr. 2021, 96, 124004. [CrossRef]

46. Ström, P.; Petersson, P.; Rubel, M.; Possnert, G. A combined segmented anode gas ionization chamber and time-of-flight detector for heavy ion elastic recoil detection analysis. Rev. Sci. Instrum. 2016, 87, 103303. [CrossRef]

47. Mayer, M. SIMNRA Users Guide. Available online: https://mam.home.ipp.mpg.de/Report\%20IPP\%209-113.pdf (accessed on 15 December 2021).

48. Rubel, M.; Coad, J.; Stenström, K.; Wienhold, P.; Likonen, J.; Matthews, G.; Philipps, V. Overview of tracer techniques in studies of material erosion, re-deposition and fuel inventory in tokamaks. J. Nucl. Mater. 2004, 329-333, 795-799. [CrossRef]

49. Coad, J.P.; Likonen, J.; Rubel, M.; Vainonen-Ahlgren, E.; Hole, D.; Sajavaara, T.; Renvall, T.; Matthews, G.; JET EFDA Contributors. Overview of material re-deposition and fuel retention studies at JET with the Gas Box divertor. Nucl. Fusion 2006, 46, 350-366. [CrossRef]

50. Heinola, K.; Widdowson, A.; Likonen, J.; Alves, E.; Baron-Wiechec, A.; Barradas, N.P.; Brezinsek, S.; Catarino, N.; Coad, P.; Koivuranta, S.; et al. Long-term fuel retention in JET ITER-like wall. Phys. Scr. 2016, T167, 014075. [CrossRef]

51. Heinola, K.; Widdowson, A.; Likonen, J.; Ahlgren, T.; Alves, E.; Ayres, C.F.; Baron-Wiechec, A.; Barradas, N.; Brezinsek, S.; Catarino, N.; et al. Experience on divertor fuel retention after two ITER-like wall campaigns. Phys. Scr. 2017, T170, 014063. [CrossRef]

52. Mayer, M.; Krat, S.; Van Renterghem, W.; Baron-Wiechec, A.; Brezinsek, S.; Bykov, I.; Coad, P.; Gasparyan, Y.; Heinola, K.; Likonen, J.; et al. Erosion and deposition in the JET divertor during the first ILW campaign. Phys. Scr. 2016, T167, 014051. [CrossRef]

53. Widdowson, A.; Coad, J.; Alves, E.; Baron-Wiechec, A.; Barradas, N.; Brezinsek, S.; Catarino, N.; Corregidor, V.; Heinola, K.; Koivuranta, S.; et al. Overview of fuel inventory in JET with the ITER-like wall. Nucl. Fusion 2017, 57, 086045. [CrossRef]

54. Widdowson, A.; Alves, E.; Baron-Wiechec, A.; Barradas, N.P.; Catarino, N.; Coad, J.; Corregidor, V.; Garcia-Carrasco, A.; Heinola, K.; Koivuranta, S.; et al. Overview of the JET ITER-like wall divertor. Nucl. Mater. Energy 2017, 12, 499-505. [CrossRef]

55. Widdowson, A.; Aleiferis, S.; Alves, E.; Avotina, L.; Baron-Wiechec, A.; Catarino, N.; Coad, J.P.; Corregidor, V.; Heinola, K.; Jepu, I.; et al. Fuel inventory and material migration of JET main chamber plasma facing components compared over three operational periods. Phys. Scr. 2020, T171, 014051. [CrossRef]

56. Krat, S.; Mayer, M.; Baron-Wiechec, A.; Brezinsek, S.; Coad, P.; Gasparyan, Y.; Heinola, K.; Jepu, I.; Likonen, J.; Petersson, P.; et al. Comparison of erosion and deposition in JET divertor during the first three ITER-like wall campaigns. Phys. Scr. 2020, T171, 014059. [CrossRef] 
57. Ivanova, D.; Rubel, M.; Widdowson, A.; Petersson, P.; Likonen, J.; Marot, L.; Alves, E.; Garcia-Carrasco, A.; Pintsuk, G.; JET EFDA Contributors. An overview of the comprehensive first mirrors test in JET with ITER-like wall. Phys. Scr. 2014, T159, 014011. [CrossRef]

58. Moon, S.; Petersson, P.; Rubel, M.; Fortuna-Zalesna, E.; Widdowson, A.; Jachmich, S.; Litnovsky, A.; Alves, E. First mirror test in JET for ITER: Complete overview after three ILW campaigns. Nucl. Mater. Energy 2019, 19, 59-66. [CrossRef]

59. Rubel, M.; Petersson, P.; Zhou, Y.; Coad, J.; Lungu, C.; Jepu, I.; Porosnicu, C.; Matveev, D.; Kirschner, A.; Brezinsek, S.; et al. Fuel inventory and deposition in castellated structures in JET-ILW. Nucl. Fusion 2017, 57, 066027. [CrossRef]

60. Brezinsek, S.; Dhard, C.P.; Jakubowski, M.; König, R.; Masuzaki, S.; Mayer, M.; Naujoks, D.; Romazanov, J.; Schmid, K.; Schmitz, O.; et al. Plasma-surface interaction in the stellarator W7-X: Conclusion drawn from operation with graphite plasmafacing components. Nucl. Fusion 2021, 62, 016006. [CrossRef]

61. Dittrich, L.; Petersson, P.; Rubel, M.; Tran, T.T.; Widdowson, A.; Jepu, I.; Porosnicu, C.; Alves, E.; Catarino, N. Fuel retention and erosion-deposition on inner wall cladding tiles in JET-ILW. Phys. Scr. 2021, 96, 124071. [CrossRef]

62. Widdowson, A.; Coad, J.P.; Zayachuk, Y.; Jepu, I.; Alves, E.; Catarino, N.; Corregidor, V.; Mayer, M.; Krat, S.; Likonen, J.; et al. Evaluation of tritium retention in plasma facing components during JET tritium operations. Phys. Scr. 2021, 96, 124075. [CrossRef]

63. Widdowson, A.; Coad, J.; Alves, E.; Baron-Wiechec, A.; Catarino, N.; Corregidor, V.; Heinola, K.; Krat, S.; Makepeace, C.; Matthews, G.; et al. Deposition of impurity metals during campaigns with the JET ITER-like wall. Nucl. Mater. Energy 2019, 19, 218-224. [CrossRef]

64. Ström, P.; Petersson, P.; Rubel, M.; Fortuna-Zalesna, E.; Widdowson, A.; Sergienko, G. Analysis of co-deposited layers with deuterium and impurity elements on samples from the divertor of JET with ITER-like wall. J. Nucl. Mater. 2019, 516, 202-213. [CrossRef]

65. Rubel, M.; Moon, S.; Petersson, P.; Widdowson, A.; A Pitts, R.; Aleiferis, S.; Fortuna-Zalesna, E.; De Temmerman, G.; Reichle, R. First mirror erosion-deposition studies in JET using an ITER-like mirror test assembly. Nucl. Fusion 2021, 61, 046022. [CrossRef]

66. Weckmann, A.; Petersson, P.; Kirschner, A.; Wienhold, P.; Brezinsek, S.; Kreter, A.; Pospieszczyk, A.; Rubel, M. Whole-machine material migration studies in the TEXTOR tokamak with molybdenum. Nucl. Mater. Energy 2017, 12, 518-523. [CrossRef]

67. Weckmann, A.; Petersson, P.; Rubel, M.; Ström, P.; Kurki-Suonio, T.; Särkimäki, K.; Kirschner, A.; Kreter, A.; Brezinsek, S.; Romazanov, J.; et al. Review of global migration, fuel retention and modelling after TEXTOR decommission. Nucl. Mater. Energy 2018, 17, 83-112. [CrossRef]

68. Weckmann, A. Material Migration in Tokamaks. Erosion-Deposition Patterns and Transport Processes. Ph.D. Thesis, KTH Royal Institute of Technology, Stockholm, Sweden, 2017.

69. Rubel, M.; Bergsåker, H.; Wienhold, P. Ion-induced release of deuterium from co-deposits by high-energy helium bombardment. J. Nucl. Mater. 1997, 241-243, 1026-1030. [CrossRef]

70. Rubel, M.; Coad, J.P.; Likonen, J.; Philipps, V. Analysis of fuel retention in plasma-facing components from controlled fusion devices. Nucl. Instrum. Methods Phys. Res. Sect. B Beam Interact. Mater. At. 2009, 267, 711-717. [CrossRef]

71. Hartwig, Z.S.; Barnard, H.S.; Sorbom, B.N.; Lanza, R.C.; Lipschultz, B.; Stahle, P.W.; Whyte, D.G. Fuel retention measurements in Alcator C-Mod using accelerator-based in situ materials surveillance. J. Nucl. Mater. 2015, 463, 73-77. [CrossRef]

72. Philipps, V.; Malaquias, A.; Hakola, A.; Karhunen, J.; Maddaluno, G.; Almaviva, S.; Caneve, L.; Colao, F.; Fortuna-Zalesna, E.; Gasior, P.; et al. Development of laser based techniques for in-situ characterization of the first wall in ITER and future fusion devices. Nucl. Fusion 2013, 53, 093002. [CrossRef] 